Provided for non-commercial research and education use. Not for reproduction, distribution or commercial use.

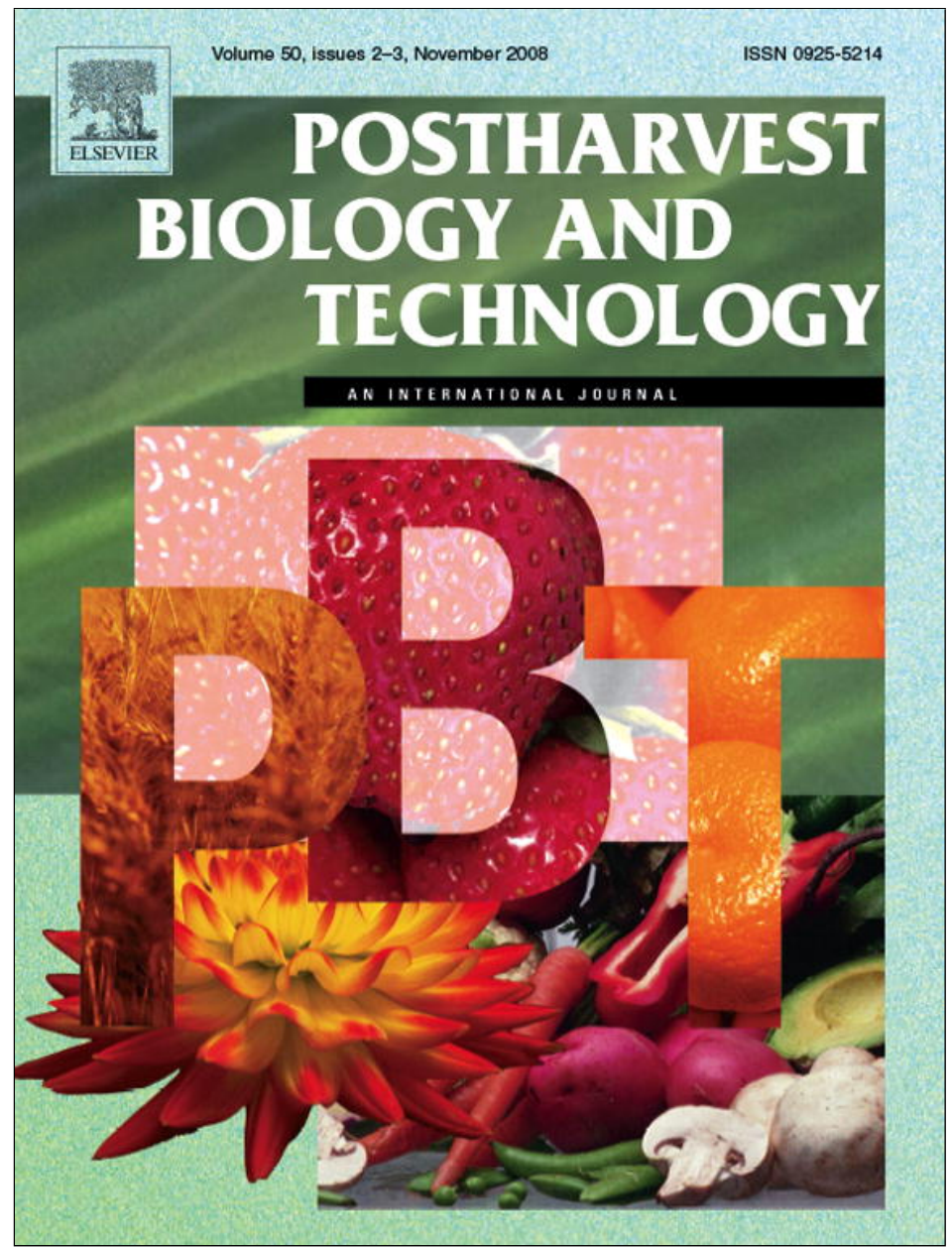

This article appeared in a journal published by Elsevier. The attached copy is furnished to the author for internal non-commercial research and education use, including for instruction at the authors institution and sharing with colleagues.

Other uses, including reproduction and distribution, or selling or licensing copies, or posting to personal, institutional or third party websites are prohibited.

In most cases authors are permitted to post their version of the article (e.g. in Word or Tex form) to their personal website or institutional repository. Authors requiring further information regarding Elsevier's archiving and manuscript policies are encouraged to visit:

http://www.elsevier.com/copyright 


\title{
Development of SCAR markers and a semi-selective medium for the quantification of strains Ach 1-1 and 1113-5, two Aureobasidium pullulans potential biocontrol agents
}

\author{
Adil El Hamouchi a,b,1, Mohammed Bajji ${ }^{\mathrm{a}, 1}$, Damien Friel $^{\mathrm{a}}$, Bouchra Najimi ${ }^{\mathrm{b}}$, El Hassan Achbani ${ }^{\mathrm{c}}$, \\ Samir El Jaafari ${ }^{\mathrm{b}}$, Alain Durieux ${ }^{\mathrm{d}}$, M. Haïssam Jijakli ${ }^{\mathrm{a}, *}$ \\ a Unité de Phytopathologie, Faculté des Sciences Agronomiques de Gembloux, Passage des Déportés 2, B-5030 Gembloux, Belgium \\ ${ }^{\mathrm{b}}$ Laboratoire de Biotechnologie et Amélioration des Plantes, Faculté des Sciences, Université Moulay Ismail, BP 4010, 50000 Meknès, Morocco \\ c Laboratoire de Phytobactériologie, Institut National de la Recherche Agronomique, BP 579, 50000 Meknès, Morocco \\ d Unité de Biotechnologie, Laboratoire de Microbiologie, Faculté des Sciences, Université Libre de Bruxelles, CP 700, Avenue Emile Gryson 1, B-1070 Bruxelles, Belgium
}

\section{A R T I C L E I N F O}

\section{Article history:}

Received 7 February 2008

Accepted 19 May 2008

\section{Keywords:}

Biological control

Monitoring

Postharvest

RAPD

SCAR

Semi-selective medium

\begin{abstract}
A B S T R A C T
Aureobasidium pullulans strains Ach 1-1 and 1113-5 are two effective biocontrol agents against Botrytis cinerea and Penicillium expansum on stored apples. In the present work, a monitoring system allowing their identification and quantification was developed. The methodology used consisted of the development of both molecular markers and a semi-selective medium. The random amplified polymorphic DNA (RAPD) technique was applied to a collection of 15 strains of $A$. pullulans, including Ach 1-1 and 1113-5. Five specific RAPD fragments were amplified for strain Ach 1-1 and three others for strain 1113-5. Among them, a fragment of $528 \mathrm{bp}$ specific to strain Ach 1-1 (generated with the OPR-13 RAPD primer) and another one of 431 bp specific to strain 1113-5 (amplified with the OPQ-03 RAPD primer) were selected, cloned, sequenced, and used to design sequence-characterized amplified region (SCAR) primers. Three different SCAR markers were amplified: two specific to strain Ach 1-1 (189 bp and $387 \mathrm{bp}$ ) and one specific to strain 1113-5 (431 bp). These SCAR primers can clearly identify strains Ach 1-1 and 1113-5 among 14 strains of A. pullulans and among eight yeast strains commonly present on apple fruit surfaces. Their selectivity was also tested using DNA extracted from epiphytic microflora of the apple surface. As a semi-selective medium, PDA medium supplemented with $0.5 \mathrm{mg} \mathrm{L}^{-1}$ euparen, $1 \mathrm{mg} \mathrm{L}^{-1}$ sumico, $2.5 \mathrm{mg} \mathrm{L}^{-1}$ hygromycin $B$, $30 \mathrm{mg} \mathrm{L}^{-1}$ streptomycin sulphate, and $1 \mathrm{mg} \mathrm{L}^{-1}$ cycloheximide was selected. It inhibited the development of the air microflora and appeared highly toxic for the epiphytic microflora of apple surface without altering the growth of the targeted strains Ach 1-1 and 1113-5. The combination of the semi-selective medium and SCAR markers provides a valuable monitoring tool to specifically identify and quantify $A$. pullulans strain Ach 1-1 and strain 1113-5 and could be used in future studies to evaluate their population dynamics under various laboratory and practical conditions.
\end{abstract}

(C) 2008 Elsevier B.V. All rights reserved.

\section{Introduction}

Aureobasidium pullulans (De Bary) Arnaud belongs to the black yeasts, a heterogeneous group defined as dematiaceous filamentous fungi (Ajello, 1977), which conquer extreme environments characterized by oligotrophic nutrient conditions, elevated temperatures, UV radiation, matrix and osmotic stress and combinations of these factors (Sterflinger, 2005). Three varieties have been rec-

\footnotetext{
* Corresponding author. Tel.: +32 81622437; fax: +32 81610126 .

E-mail address: jijakli.h@fsagx.ac.be (M.H. Jijakli).

1 These authors have equally contributed to this work.
}

ognized: A. pullulans var. pullulans, A. pullulans var. melanogenicum (Hermanides-Nijhof, 1977), and A. pullulans var. aubasidani (Yurlova and de Hoog, 1997). From an ecological point of view, A. pullulans is a ubiquitous species found mainly on the phylloplane and has been isolated from different samples and substrates (Domsch et al., 1980). Some A. pullulans strains are of commercial interest because of their biosynthesis of pullulan, an extracellular polysaccharide (Lee et al., 1999). Several other strains have been considered as potential biocontrol agents against the main postharvest pathogens (e.g. Botrytis cinerea and Penicillium expansum) on several important crops, including apple (Leibinger et al., 1997; Ippolito et al., 2000; Castoria et al., 2001; Achbani et al., 2005; Krimi Bencheqroun et al., 2007). 
In this context, A. pullulans strains Ach 1-1 and 1113-5 were isolated from 'Golden Delicious' apples for their high antagonistic activity (more than $80 \%$ ) against $B$. cinerea and $P$. expansum, two major postharvest pathogens of apples (Achbani et al., 2005). With regard to strain Ach 1-1, a process suitable for producing large quantities has been developed (Mounir et al., 2007) and competition for apple nutrients, most particularly amino acids, may be the main mechanism of its biocontrol activity against blue mold caused by $P$. expansum on harvested apple fruit (Krimi Bencheqroun et al., 2007). The practical application of Ach 1-1 and 1113-5 strains as biocontrol agents will require the development of monitoring methods allowing their specific identification and their quantification. Such methods will be very useful to study the efficacy, the ecological fitness and the environmental fate of these strains once applied on apples. They will also contribute to the establishment of a quality control procedure for the biofungicide and may facilitate the registration procedure.

Several monitoring methods have been developed to identify and to quantify microorganisms, the choice of the method being dependent on the required level of specificity. In the case of biocontrol agents, a strain-specific detection level is needed as they are released into the environment where other strains of the same species of the biocontrol agent may be present. Among microbiological monitoring methods, counting colony forming units (cfu) after dilution plating on selective or semi-selective media has been frequently and successfully used to monitor population size of biocontrol agents (Donegan et al., 1991; Teixido et al., 1999; Nunes et al., 2008). This method, although simple and cheap, is based on morphological and cultural characteristics of strains and may thus not be able to differentiate between strains having the same characteristics. In the case of $A$. pullulans, such a shortcoming may be particularly significant because of its high genetic variability and its wide distribution in both the phyllosphere and the carposphere (Yurlova et al., 1995; Schena et al., 1999; Urzi et al., 1999). The development of PCR-based molecular markers allowing the detection of a specific DNA sequence of the target strain offers the possibility to differentiate it from closely related strains of the same species (Olive and Bean, 1999). Random amplified polymorphic DNA (RAPD) (Williams et al., 1990) remains the most commonly used method to distinguish between several strains within the same species because of its easy use and of its high discrimination power (Olive and Bean, 1999; Urzi et al., 1999). As RAPD is based on the use of a short single primer for the amplification of genomic DNA under nonrestrictive conditions, the lack of reproducibility remains its major drawback. However, the transformation of RAPD primers into sequence-characterized amplified regions (SCAR) primers (Paran and Michelmore, 1993) has allowed a reproducible amplification of one specific single DNA fragment (Schena et al., 2002; Loncaric et al., 2008).

Rather than using one of the above-mentioned monitoring methods, more and more work reports on the combination of the advantages of dilution plating methods on (semi-)selective media with strain-specific identification by SCAR markers (Abbasi et al., 1999; De Clercq et al., 2003; Pujol et al., 2005; Nunes et al., 2008). In this context, the main objective of the present study was to develop (i) specific SCAR markers using the RAPD technique, and (ii) a semiselective medium as a mixed monitoring system to identify and quantify populations of $A$. pullulans strains Ach 1-1 and 1113-5.

\section{Materials and methods}

\subsection{Yeast strains and culture conditions}

Table 1 shows the original substrates and sources of the different strains used in the present work. A. pullulans strains Ach 1-1, Ach 2-1, Ach 2-2, and A. pullulans var. pullulans strains 11135 and 1113-10 were isolated from the surface of 'Golden Delicious' apples (Achbani et al., 2005). The other strains of A. pullulans were obtained from the collection of the 'Mycothèque de l'Université Catholique de Louvain' (MUCL, Belgium). Other strains belonging to four different species were also considered (Table 1). All the strains were stored at $-80^{\circ} \mathrm{C}$ in $25 \%$ glycerol for a long-term storage, and on Potato Dextrose Agar (PDA) medium (Merck, Darmstadt, Germany) at $4{ }^{\circ} \mathrm{C}$ for a short-term storage. Before each experiment,

Table 1

Origin and source of yeast strains used in the present study

\begin{tabular}{|c|c|c|c|}
\hline Yeast species & Strain & Original substrate & Source \\
\hline Aureobasidium pullulans & $\begin{array}{l}\text { Ach 1-1 } \\
\text { Ach 2-1 } \\
\text { Ach 2-2 } \\
\text { MUCL } 22377 \\
\text { MUCL } 20326 \\
\text { MUCL } 20322 \\
\text { MUCL } 6147\end{array}$ & $\begin{array}{l}\text { Apple, Golden Delicious (Belgium) } \\
\text { Leaves, Quercus robur (Sweden) } \\
\text { Leaves, Hordeum sativum (Belgium) } \\
\text { Tuiles (The Netherlands) } \\
\text { Picea abies (Norway) }\end{array}$ & $\begin{array}{l}\text { Plant Pathology Unit (FUSAGx, Belgium) } \\
\text { MUCL (Louvain-la-Neuve, Belgium) }\end{array}$ \\
\hline A. pullulans var. pullulans & $\begin{array}{l}\text { MUCL } 7862 \\
1113-5 \\
1113-10 \\
1206-5\end{array}$ & $\begin{array}{l}\text { Cupule, Fagus sylvatica (Belgium) } \\
\text { Apple, Golden Delicious (Morocco) }\end{array}$ & INRA (Meknès, Morocco) \\
\hline A. pullulans var. melanogenum & $\begin{array}{l}\text { MUCL } 8724 \\
\text { MUCL } 19714 \\
\text { MUCL } 19360 \\
\text { MUCL } 43163\end{array}$ & $\begin{array}{l}\text { Soil (Zaire) } \\
\text { Fruit, Symphoricarpos rivularis (Sweden) } \\
\text { Tree, Xyloterus lineatus (Belgium) } \\
\text { Leaves and stem, Citurs sinensis (Brazil) }\end{array}$ & MUCL (Louvain-la-Neuve, Belgium) \\
\hline Pichia anomala & $\begin{array}{l}\mathrm{K} \\
\mathrm{J} 121\end{array}$ & $\begin{array}{l}\text { Apple, Golden Delicious (Belgium) } \\
\text { Cereals }\end{array}$ & $\begin{array}{l}\text { Plant Pathology Unit (FUSAGx, Belgium) } \\
\text { Department of Microbiology (SUAS, Sweden) }\end{array}$ \\
\hline Candida oleophila & $\begin{array}{l}\mathrm{O} \\
\mathrm{I}-128\end{array}$ & $\begin{array}{l}\text { Apple, Golden Delicious (Belgium) } \\
\text { Apple }\end{array}$ & $\begin{array}{l}\text { Plant Pathology Unit (FUSAGx, Belgium) } \\
\text { Aspire }^{\mathrm{TM}} \text { (Ecogen, Langhorne, USA) }\end{array}$ \\
\hline Candida sake & $\begin{array}{l}\text { CBS } 2213 \\
\text { CBS } 159\end{array}$ & $\begin{array}{l}\text { Unknown } \\
\text { Unknown }\end{array}$ & CBS-KNAW (Utrecht, The Netherlands) \\
\hline Debaryomyces hansenii & $\begin{array}{l}\text { MUCL } 29030 \\
\text { MUCL } 29907\end{array}$ & $\begin{array}{l}\text { French cheese } \\
\text { Human skin }\end{array}$ & MUCL (Louvain-la-Neuve, Belgium) \\
\hline
\end{tabular}


strains were grown on PDA medium for three subcultures of $48 \mathrm{~h}$ at $25^{\circ} \mathrm{C}$.

\subsection{Identification of molecular markers}

\subsubsection{DNA extraction}

Strains were allowed to grow on YEPD medium (1\% yeast extract, $2 \%$ peptone, $2 \%$ dextrose; Merck) with rotatory shaking at $25^{\circ} \mathrm{C}$ for $24 \mathrm{~h}$. Genomic DNA of the different strains (Table 1 ) was isolated according to Ausubel et al. (1987) with minor modifications. Cell cultures $(10 \mathrm{~mL})$ were centrifuged for $10 \mathrm{~min}$ at room temperature at $3000 \mathrm{rpm}$ in a Sorval GSA rotor and the pellets were suspended in $500 \mu \mathrm{L}$ of sterile distilled water. This step (centrifugation/washing) was performed twice and yeast cells were resuspended in $200 \mu \mathrm{L}$ of breaking buffer ( $2 \%$ Triton X-100, $1 \%$ SDS, $100 \mathrm{mM} \mathrm{NaCl}, 10 \mathrm{mM}$ Tris- $\mathrm{HCl} \mathrm{pH}$ 8.0, $1 \mathrm{mM}$ EDTA pH 8.0). The cell suspension was vortexed for $20 \mathrm{~min}$ in the presence of $0.3 \mathrm{~g}$ of acid-washed glass beads (425-600 $\mu \mathrm{m}$ diameter) and $200 \mu \mathrm{L}$ of phenol/chloroform/isoamyl alcohol (25:24:1), and then centrifuged at $15,700 \mathrm{~g}$ for $5 \mathrm{~min}$ at $4{ }^{\circ} \mathrm{C}$ after addition of $200 \mu \mathrm{L}$ TE X-1 ( $10 \mathrm{mM}$ Tris-HCl, $1 \mathrm{mM}$ EDTA, $\mathrm{pH}$ 8.0). The aqueous phase was recovered and DNA was precipitated with $100 \%$ cold ethanol $\left(-20^{\circ} \mathrm{C}\right)$. The pellet was suspended in $400 \mu \mathrm{L}$ of TE X-1, incubated for $30 \mathrm{~min}$ at $55^{\circ} \mathrm{C}$ and then submitted for $2 \mathrm{~min}$ at $37^{\circ} \mathrm{C}$ to deoxyribonuclease-free ribonuclease $\left(1 \mathrm{mg} \mathrm{mL}^{-1}\right)$. DNA was precipitated with two volumes of cold absolute ethanol $\left(-20^{\circ} \mathrm{C}\right)$ in the presence of one-tenth volume of $4 \mathrm{M}$ ammonium acetate, dried and dissolved in $50 \mu \mathrm{L}$ TE X-1.

Genomic DNA of microorganisms living on the surface of apple fruit ('Golden Delicious') was also extracted. Three untreated apples and two treated (with strain Ach 1-1 or strain 1113-5) ones (positive controls) were separately washed in $300 \mathrm{~mL}$ of KPB buffer [ $16 \mathrm{mM}$ $\mathrm{K}_{2} \mathrm{HPO}_{4}, 34 \mathrm{mM} \mathrm{KH}_{2} \mathrm{PO}_{4}$ and $0.05 \%$ Tween $80, \mathrm{pH} 6.5$ ] for $20 \mathrm{~min}$ at $120 \mathrm{rpm}$ on a rotatory shaker (Gerhardt, Germany). Washing water resulting from each apple was filtered $\left(0.45 \mu \mathrm{m}\right.$, Supor ${ }^{\circledR}$, Gelman Sciences, Ann Harbor, USA) and the cells were recovered in $1.5 \mathrm{~mL}$ of KPB buffer by vortexing during $10 \mathrm{~min}$. The cell suspension was subsequently subjected to total DNA extraction as described above.

\subsubsection{RAPD analysis}

RAPD primers used in this study were obtained from Operon Technologies Inc. (Alameda, California). In the first round of amplifications, Ach 1-1 was used as the targeted strain and 39 random primers (detailed sequences not shown) were tested. In the second round of amplifications, 60 primers (detailed sequences not shown) were tested using 1113-5 as the targeted strain. The PCR reactions were performed in a $25 \mu \mathrm{L}$ mixture containing $1.0 \mathrm{U}$ of Taq DNA polymerase (Sigma-Aldrich, Inc, USA), $1 \times$ PCR buffer Sigma (containing $2.5 \mathrm{mM} \mathrm{MgCl}_{2}$ ), $100 \mu \mathrm{M}$ of each dNTP, $2.5 \mathrm{mM} \mathrm{MgCl}_{2}$, $0.5 \mu \mathrm{M}$ RAPD primer and $50 \mathrm{ng}$ genomic DNA. Amplifications were performed in a thermal cycler (PTC 200, MJ Research Inc., USA), starting with an initial denaturation step at $94{ }^{\circ} \mathrm{C}$ for $5 \mathrm{~min}$, followed by 44 cycles at $94^{\circ} \mathrm{C}$ for $15 \mathrm{~s}, 36^{\circ} \mathrm{C}$ for $45 \mathrm{~s}$ and $72^{\circ} \mathrm{C}$ for $90 \mathrm{~s}$ with a final extension step at $72{ }^{\circ} \mathrm{C}$ for $10 \mathrm{~min}$. Aliquots $(10 \mu \mathrm{L})$ of PCR products were subjected to electrophoresis on $1.5 \%$ agarose gel in $1 \times$ TBE buffer ( 89 mM Tris-Borate, 2 mM EDTA, pH 8.0) and visualized by staining with $1 \mu \mathrm{g} \mathrm{mL} \mathrm{m}^{-1}$ ethidium bromide.

\subsubsection{Cloning and sequencing of RAPD markers}

RAPD bands specific to strain Ach 1-1 and strain 1113-5 were respectively obtained with RAPD primers OPR-13 (5'GGACGACAAG-3') and OPQ-03 (5'-GGTCACCTCA-3'). These bands were excised from the gel and DNA was purified using the QIAEX II DNA Purification Kit (Qiagen, Germany) according to the manufacturer instructions. DNA fragments were ligated into the pCR 2.1 vector, and then used to transform competent cells of Escherichia
Table 2

Description of SCAR primers used for A. pullulans strains Ach 1-1 and 1113-5

\begin{tabular}{llllc}
\hline Strain $^{\mathrm{a}}$ & Code & Sequence $\left(\right.$ 5' $^{\prime}$-3' $\left.^{\prime}\right)$ & Size (bp) & Position $^{\text {b }}$ \\
\hline Ach 1-1 & AR13.1 & GACGACAAGAAAACTGGATCATGT & 24 & $2-25$ \\
& AR13.2 & GGACGACAAGCTGAGGAGCG & 20 & $509-528$ \\
& AR13.3 & ACTCCAACTCCTGACGATG & 20 & $77-96$ \\
& AR13.4 & GGTATCGCTGACCTCGTTGT & 20 & $227-246$ \\
& AR13.5 & CAGAAGTCAGAGGACCAGTCA & 21 & $49-69$ \\
& AR13.6 & TCGCACATACAACACGACTTG & 21 & $472-492$ \\
& AR13.7 & CACCCGGTATTCCACTTCCAC & 21 & $105-125$ \\
& AR13.8 & CAGCAGCGGGGGAGCTCGAT & 20 & $451-470$ \\
& AR13.9 & CACCACGCAGCGAGAAGTCA & 20 & $336-355$ \\
& AR13.10 & GTGGTTCCCATGTATTGTCTGA & 22 & $273-294$ \\
& AR13.11 & CATACAACACGACTTGTCAGC & 21 & $467-487$ \\
& AQ3.1 & GTCACCTCAAGAAATATATTGTC & 23 & $1-23$ \\
& AQ3.2 & GGTCACCTCATTATATCAGTGG & 22 & $410-431$ \\
& AQ3.3 & AGAGACCGTTGTGGGCTTTAG & 21 & $186-206$ \\
& AQ3.4 & AGTCCTGCCATTTGAGATCG & 20 & $339-358$ \\
& AQ3.5 & ATTATCGGAGGCTGGTCGCA & 20 & $160-179$ \\
& AQ3.6 & CGAATCCCTTCCAACTTGTCC & 21 & $303-323$ \\
& AQ3.7 & CGAGGCCTTTCACACAATAACC & 22 & $251-272$ \\
& AQ3.8 & CCTCATGCGACCAGCCTCCG & 20 & $165-184$ \\
\hline
\end{tabular}

a Targeted strain.

b Position on sequenced RAPD markers obtained for strains Ach 1-1 and 1113-5 using respectively OPR-13 and OPQ-03 RAPD primers.

coli strain INV $\alpha \mathrm{F}^{\prime}$ using the TA Cloning kit (Invitrogen, USA). The ULTRAPrep ${ }^{\circledR}$ Plasmid DNA kit (AHN Biotechnologie, Germany) was used to isolate recombinant plasmids according to the included protocol. Inserts were sequenced in both directions using the Big Dye Terminator 3.1 Cycle Sequencing kit (Applied Biosystems, USA).

\subsubsection{Generation of SCAR markers}

SCAR primers tested for the two targeted strains (Ach 1-1 and 1113-5) are described in Table 2. AR13.1 and AR13.2 SCAR primers are derived from OPR-13 RAPD primer elongation. Similarly, AQ3.1 and AQ3.2 are issued from OPQ-03 extension. The other primers were designed using the online Primer3 software and the sequenced RAPD markers as DNA sequence source. Thirteen SCAR primer pairs for strain Ach 1-1 (AR13.1/AR13.2, AR13.3/AR13.4, AR13.5/AR13.6, AR13.1/AR13.4, AR13.3/AR13.2, AR13.5/AR13.2, AR13.3/AR13.6, AR13.5/AR13.4, AR13.7/AR13.10, AR13.9/AR13.8, AR13.7/AR13.8, AR13.9/AR13.11, and AR13.7/AR13.11) and 12 for strain 1113-5 (AQ3.1/AQ3.2, AQ3.1/AQ3.4, AQ3.1/AQ3.6, AQ3.1/ AQ3.8, AQ3.3/AQ3.2, AQ3.3/AQ3.4, AQ3.3/AQ3.6, AQ3.5/AQ3.2, AQ3.5/AQ3.4, AQ3.5/AQ3.6, AQ3.7/AQ3.2, and AQ3.7/AQ3.4) were tested on the total yeast collection listed in Table 1 under optimised PCR amplification conditions [ $1 \times$ PCR buffer (Roche), $0.2 \mathrm{mM}$ dNTP, $0.4 \mu \mathrm{M}$ forward and reverse primers, 1.0 U Taq DNA polymerase (Roche), $50 \mathrm{ng}$ genomic DNA in a final volume of $50 \mu \mathrm{L}]$. The thermal cycle consisted in $5 \mathrm{~min}$ of denaturation at $94^{\circ} \mathrm{C}$, followed by 35 cycles of $30 \mathrm{~s}$ at $94^{\circ} \mathrm{C}, 45 \mathrm{~s}$ at $62^{\circ} \mathrm{C}, 45 \mathrm{~s}$ at $72{ }^{\circ} \mathrm{C}$ and a final elongation for $5 \mathrm{~min}$ at $72^{\circ} \mathrm{C}$.

Once specific SCAR markers developed (see Section 3), the corresponding primer pairs (AR13.7/AR13.10 and AR13.7/AR13.11 for strain Ach 1-1, AQ3.1/AQ3.2 for strain 1113-5) were tested on genomic DNA extracted from the epiphytic microflora of apple surface in the same amplification conditions as detailed above.

\subsection{Development of a semi-selective medium}

For the development of a semi-selective medium using Ach 11 as the targeted strain, eight fungicides and six antibiotics were tested at different concentrations (Table 3 ) using PDA as the basal medium. Fungicides and antibiotics were first tested individually and then in combination of 3-5 different compounds (detailed description of combinations not shown). On the whole, 40 differ- 
Table 3

Description of fungicides and antibiotics used for the development of a semi-selective medium for A. pullulans strain Ach 1-1

\begin{tabular}{|c|c|c|c|}
\hline Product type & Product name (active substances) & Concentration $\left(\mathrm{mg} \mathrm{L}^{-1}\right)$ & Code \\
\hline \multirow[t]{8}{*}{ Fungicides } & Sumico (Diethofencarb + Carbendazim) & $1,1.5,5,10,25,50,100$ & Su \\
\hline & Fungaflor (Imazalil) & $0.25,0.5,1,5,10$ & $\mathrm{Fu}$ \\
\hline & Topsin (Thiophanate-methyl) & $0.25,0.5,1,5,10$ & To \\
\hline & Captan (Captan) & $0.25,0.5,1,5,10$ & $\mathrm{Ca}$ \\
\hline & TMTD (Thiram) & $0.25,0.5,1,1.5,2.5$ & $\operatorname{Tm}$ \\
\hline & Lirotect (Thiabendazole) & $2.5,5,10,25$ & $\mathrm{Li}$ \\
\hline & Euparen (Tolylfluanide) & $0.1,0.25,0.5$ & Eu \\
\hline & Pelt 44 (Thiophanate-methyl) & $0.5,1,5$ & $\mathrm{Pe}$ \\
\hline \multirow[t]{6}{*}{ Antibiotics } & Cycloheximid & $0.1,0.25,0.5,1,1.5,2.5,5,10$ & Cy \\
\hline & Geneticin & $2.5,5,10,25,50,100$ & $\mathrm{Ge}$ \\
\hline & Hygromycin B & $2.5,5,10,50,100$ & Hy \\
\hline & Tetracyclin & $10,25,50$ & $\mathrm{Te}$ \\
\hline & Spectinomycin & $10,25,50$ & Sp \\
\hline & Streptomycin sulphate & $10,25,30,50$ & St \\
\hline
\end{tabular}

ent media were tested. Toxicity of each medium was evaluated and compared to PDA medium upon plating $100 \mathrm{cfu}$ of strain Ach 1-1 (four replicates per medium). Concentration $\left(\mathrm{cfu} \mathrm{mL}^{-1}\right.$ ) of strain Ach 1-1 suspension was determined using the Bürker cell. The number of cfu was recorded 3,4 and $7 \mathrm{~d}$ after incubation at $25^{\circ} \mathrm{C}$. Plating efficiency of strain Ach 1-1 on each medium was calculated according to the following formula:

Efficiency $(\%)=\left[\frac{(\text { cfu on the tested medium })}{(\text { cfu on PDA medium })}\right] \times 100$

To evaluate the selectivity of the different media against the laboratory air microflora, three Petri dishes per medium, including PDA, were left open for $3 \mathrm{~h}$ on the laboratory bench. The selectivity of each medium was also evaluated against apple fruit microflora. To this end, four untreated apples were separately washed with $300 \mathrm{~mL}$ of KPB buffer on a rotatory shaker (Gerhardt, Germany) at $120 \mathrm{rpm}$ during $20 \mathrm{~min}$. Three millilitres were collected from each washing water and pooled for the four apples. Four-fold dilutions were plated out in quadruplicate on the tested media as well as on PDA basal medium. After one week of incubation at $25^{\circ} \mathrm{C}$, the different colonies issued from either the laboratory or the fruit microflora were visually observed and counted.

Once a semi-selective medium developed for strain Ach 1-1, its toxicity was assessed on strain 1113-5.

\section{Results}

\subsection{Identification of strain-specific RAPD markers}

In a first round of amplifications, Ach 1-1 was used as the targeted strain. Thirty nine RAPD primers were first tested on genomic DNA of Ach 1-1 and two other strains (Ach 2-1 and Ach 2-2) (detailed data not shown). Eight primers were selected (OPP-01, OPQ-04, OPQ-12, OPR-06, OPR-13, OPT-01, OPT-05 and OPT-17) based on their ability to generate at least one DNA fragment specific to the strain Ach 1-1. The size of specific bands ranged from 0.5 to $2.6 \mathrm{kbp}$. These primers were then assessed on the complete A. pullulans collection (Table 1) except 1113-5, 1113-10 and 1206-5. Among them, five produced each one fragment specific to strain Ach 1-1 (Table 4). These fragments constitute thus five potential Ach 1-1-specific SCAR markers. The RAPD pattern obtained with OPR-13 primer is shown in Fig. 1. Depending on the strain, 8-22 DNA fragments ranging from 0.4 to $3.2 \mathrm{kbp}$ have been amplified. The Ach 1-1-specific fragment (Fig. 1) was cloned and sequenced, leading to a sequence of $528 \mathrm{bp}$.
Table 4

RAPD primer code and sequence and size of the corresponding specific bands generated for each targeted strain

\begin{tabular}{llll}
\hline Targeted strain & RAPD primer & Sequence $\left(5^{\prime}-3^{\prime}\right)$ & Size of specific bands (bp) \\
\hline Ach 1-1 & OPQ-04 & AGTGCGCTGA & 1060 \\
& OPQ-12 & AGTAGGGCAC & 875 \\
& OPR-13 & GGACGACAAG & 525 \\
& OPT-01 & GGGCCACTCA & 525 \\
& OPT-17 & CCAACGTCGT & 1300 \\
$1113-5$ & OPN-17 & CATTGGGGAG & 460 \\
& OPO-05 & CCCAGTCACT & 500 \\
& OPQ-03 & GGTCACCTCA & 431 \\
\hline
\end{tabular}

In the second round of amplifications, 1113-5 was the targeted strain. Its RAPD pattern was first compared to that of two other strains (1113-10 and Ach 1-1) using 60 different RAPD primers (detailed data not presented). Sixteen primers produced at least one band specific to the strain 1113-5, the size of these bands ranging between 0.4 and $1.4 \mathrm{kbp}$. Among them, eight (OPN-17, OPO-05, 0PP14, OPQ-03, OPR-06, OPR-20, OPT-02 and OPT-06) were screened using the whole collection of $A$. pullulans (Table 1 ). Three primers have generated each one 1113-5-specific band (Table 4). The RAPD profile obtained with $\mathrm{OPQ}-03$ produced a reproducible fragment of 431 bp (Fig. 2) which was successfully cloned and sequenced.

The RAPD patterns obtained with OPR-13 primer for strain Ach 1-1 and with OPQ-03 for 1113-5 were reproducible on three inde-

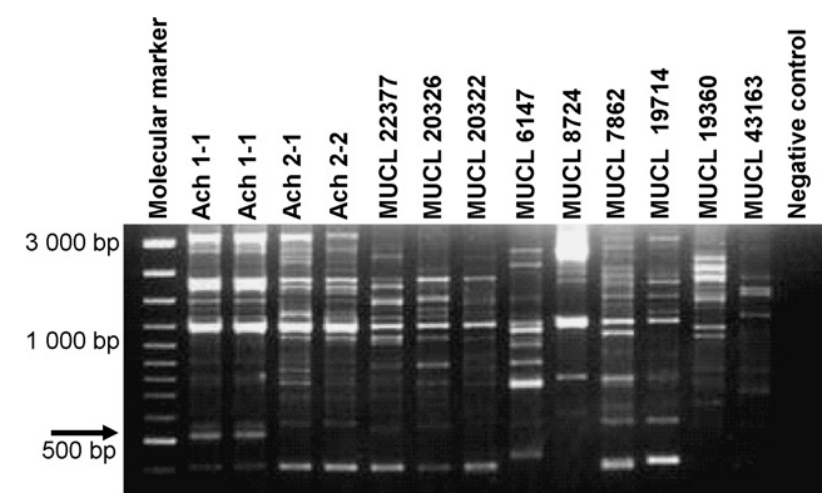

Fig. 1. RAPD patterns of $A$. pullulans strains obtained with OPR-13 primer. Negative control: addition of sterile water to the PCR mix. Molecular marker: Generuler ${ }^{\mathrm{TM}}$ 100 bp DNA Ladder Plus (Fermentas). The arrow indicates the band specific to strain Ach 1-1. 


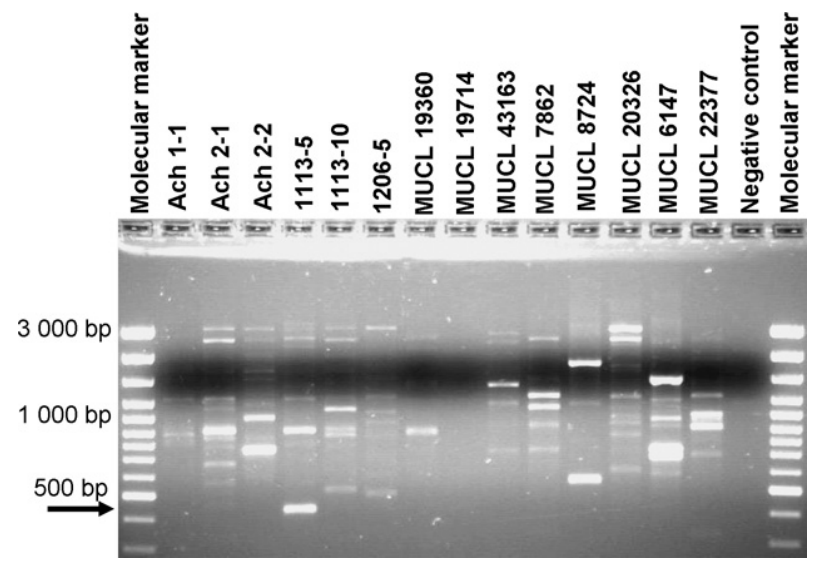

Fig. 2. RAPD patterns of $A$. pullulans strains obtained with $\mathrm{OPQ}-03$ primer. Negative control: addition of sterile water to the PCR mix. Molecular marker: Generuler ${ }^{\mathrm{TM}}$ 100 bp DNA Ladder Plus (Fermentas). The arrow indicates the band specific to strain 1113-10.

pendent DNA preparations (results not shown). These primers were thus selected for the development of SCAR markers.

\subsection{Generation of SCAR markers}

To obtain SCAR markers specific to strain Ach 1-1 or to strain 1113-5, we designed 11 SCAR primers targeting the strain Ach 1-1 and 8 SCAR primers targeting the strain 1113-5, derived respectively from the sequences of the strain-specific RAPD markers amplified with OPR-13 and OPQ-03 primers (Table 2). In this work, a total of 25 combinations of SCAR primer pairs (13 for strain Ach 1-1 and 12 for strain 1113-5) were tested.

The specificity of SCAR primers was checked on 14 A. pullulans strains of our collection (Table 1). In the case of strain Ach 1-1, both primer pairs AR13.7/AR13.10 and AR13.7/AR13.11 produced respectively specific SCAR markers of $189 \mathrm{bp}$ (Fig. 3) and $387 \mathrm{bp}$ (data not shown) at an annealing temperature of $62^{\circ} \mathrm{C}$. For strain 1113-5, a unique fragment of $431 \mathrm{bp}$ was obtained with AQ3.1/AQ3.2 primer pair at an annealing temperature of $60^{\circ} \mathrm{C}$ (Fig. 4). Other primer pairs were also screened but no strain-specific amplification was observed neither for Ach 1-1 nor for 1113-5 (data not shown). The SCAR primer pairs AR13.7/AR13.10, AR13.7/AR13.11 and AQ3.1/AQ3.2 were also tested on genomic DNA extracted from eight strains belonging to different yeast species commonly iso-

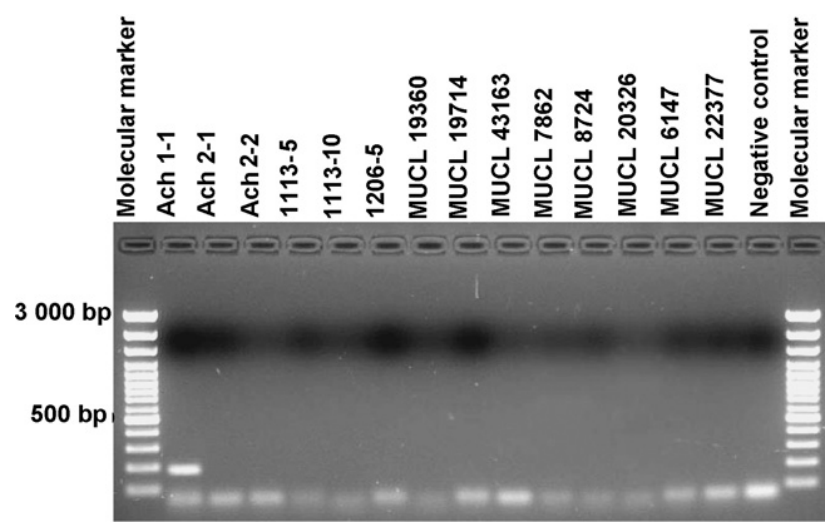

Fig. 3. Amplification of a SCAR marker specific to strain Ach 1-1 using AR13.7/AR13.10 as a primer pair. Negative control: addition of sterile water to the PCR mix. Molecular marker: Generuler ${ }^{\mathrm{TM}} 100$ bp DNA Ladder Plus (Fermentas).

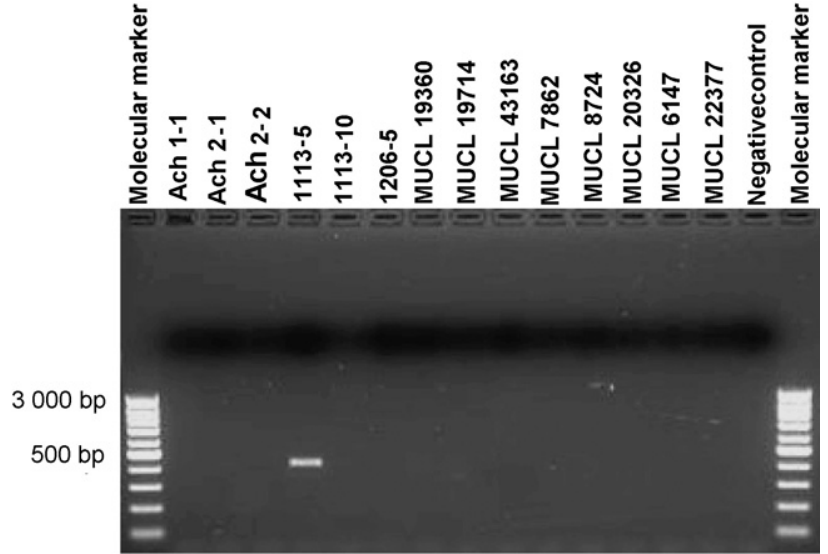

Fig. 4. Amplification of a SCAR marker specific to strain 1113-5 using AQ3.1/AQ3.2 as a primer pair. Negative control: addition of sterile water to the PCR mix. Molecular marker: Generuler ${ }^{\mathrm{TM}} 100$ bp DNA Ladder Plus (Fermentas).

lated from apple surface (Table 1) as well as on DNA extracted from the epiphytic microflora of apple surface and no amplification was obtained (data not shown).

The reproducibility of the SCAR patterns was confirmed using three different DNA preparations (data not shown).

\subsection{Development of a semi-selective medium}

A total of 40 combinations of fungicides and antibiotics were tested on strain Ach 1-1. Their potential toxicity was evaluated by growing strain Ach 1-1 on the tested media and on PDA during $7 \mathrm{~d}$ at $25^{\circ} \mathrm{C}$. Ternary, quaternary and quinary combinations were carried out starting from the highest concentration of antibiotics and fungicides known as nontoxic when used alone for strain Ach 11. The results of some nontoxic combinations (percentage of plating efficiency superior to 90\%) for the strain Ach 1-1 are presented in Table 5.

Strain Ach 1-1 was unable to recover on one combination only ( $1 \mathrm{mg} \mathrm{L}^{-1}$ euparen $+1.5 \mathrm{mgL}^{-1}$ sumico $+2.5 \mathrm{mg} \mathrm{L}^{-1}$ hygromycin $\mathrm{B}+25 \mathrm{mg} \mathrm{L}^{-1}$ streptomycin sulphate). For other tested combinations, the plating efficiency ranged from $58 \%$ to $95 \%$ for 15 combinations and reached approximately $100 \%$ for the remaining combinations, including the combination $\mathrm{S}_{32}\left(0.5 \mathrm{mg} \mathrm{L}^{-1}\right.$ euparen $+1 \mathrm{mgL}^{-1}$ sumico $+2.5 \mathrm{mgL}^{-1}$ hygromycin $\mathrm{B}+30 \mathrm{mg} \mathrm{L}^{-1}$ streptomycin sulphate $+1 \mathrm{mg} \mathrm{L}^{-1}$ cycloheximide) (Table 5).

Selectivity of nontoxic combinations for strain Ach 1-1 was then evaluated on the air microflora. Only the $S_{32}$ medium showed total inhibition against the air microflora and an important inhibition

Table 5

Plating efficiency (\%) of A. pullulans strain Ach 1-1 on some tested media

\begin{tabular}{llc}
\hline Medium code & Compound $^{\mathrm{a}}$ combination $\left(\mathrm{mg} \mathrm{L}^{-1}\right)$ & Plating efficiency (\%) \\
\hline $\mathrm{S}_{2}$ & $\mathrm{Li}(10)+\mathrm{Tm}(1)+\mathrm{Sp}(25)+\mathrm{Te}(50)$ & $107.8 \pm 16.8^{\mathrm{c}}$ \\
$\mathrm{S}_{5}$ & $\mathrm{Pe}(5)+\mathrm{Eu}(0.5)+\mathrm{St}(25)+\mathrm{Hy}(5)$ & $95.0 \pm 2.0$ \\
$\mathrm{~S}_{7}$ & $\mathrm{Tm}(1)+\mathrm{Sp}(25)+\mathrm{St}(25)$ & $92.2 \pm 17.6$ \\
$\mathrm{~S}_{14}$ & $\mathrm{Su}(1.5)+\mathrm{Tm}(1.5)+\mathrm{Cy}(1.5)+\mathrm{Te}(50)$ & $98.6 \pm 14.5$ \\
$\mathrm{~S}_{16}$ & $\mathrm{Su}(1.5)+\mathrm{Tm}(1.5)+\mathrm{St}(30)+\mathrm{Ge}(2.5)$ & $101.4 \pm 19.2$ \\
$\mathrm{~S}_{17}$ & $\mathrm{Su}(1.5)+\mathrm{Tm}(1.5)+\mathrm{Te}(50)+\mathrm{Ge}(2.5)$ & $102.7 \pm 16.4$ \\
$\mathrm{~S}_{18}$ & $\mathrm{Eu}(0.5)+\mathrm{Su}(1)+\mathrm{Hy}(2.5)+\mathrm{St}(30)$ & $102.7 \pm 13.2$ \\
$\mathrm{~S}_{32}$ & $\mathrm{Eu}(0.5)+\mathrm{Su}(1)+\mathrm{Hy}(2.5)+\mathrm{St}(30)+\mathrm{Cy}(1)$ & $98.7 \pm 8.7$ \\
\hline
\end{tabular}

Only media with plating efficiency superior to $90 \%$ are shown.

a Lirotect (Li), TMTD (Tm), Sumico (Su), Euparen (Eu), Hygromycin B (Hy), Streptomycin sulphate (St), Tetracyclin (Te), Cycloheximid (Cy), Geneticin (Ge), Spectinomycin (Sp).

b Efficiency $(\%)=[($ cfu on the tested medium $) /($ cfu on PDA medium $)] \times 100$.

c Mean \pm S.E. 


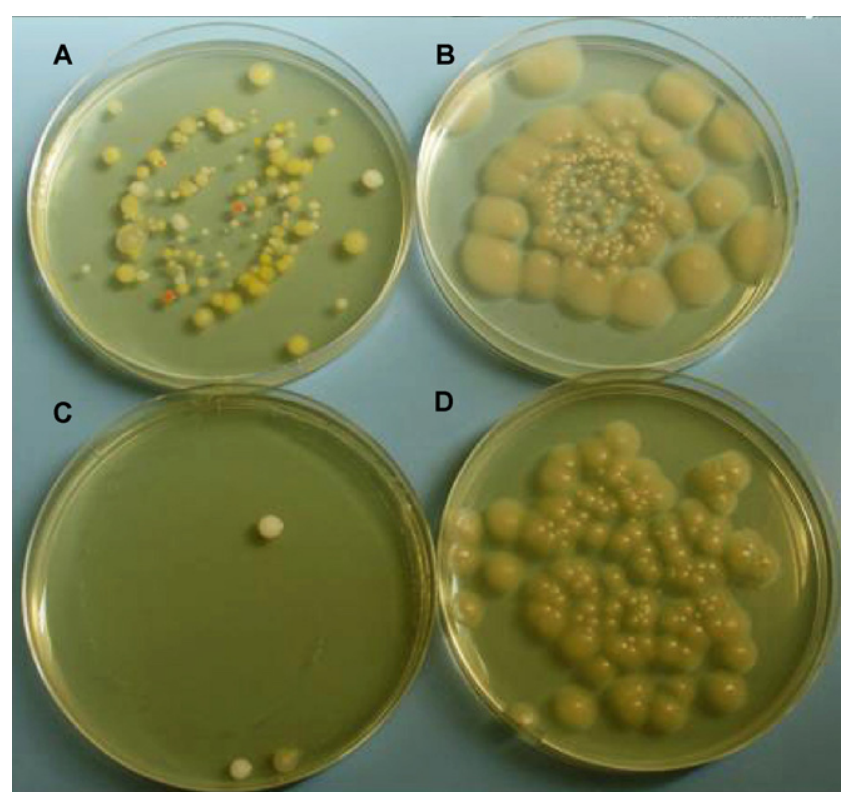

Fig. 5. Qualitative test of the selectivity and toxicity of $S_{32}$ medium $\left(0.5 \mathrm{mg} \mathrm{L}^{-1}\right.$ euparen $+1 \mathrm{mg} \mathrm{L}^{-1}$ sumico $+2.5 \mathrm{mg} \mathrm{L}^{-1}$ hygromycin $\mathrm{B}+30 \mathrm{mg} \mathrm{L}^{-1}$ streptomycin sulphate $+1 \mathrm{mg} \mathrm{L}^{-1}$ cycloheximide) (B, C and $\mathrm{D}$ ) compared to natural occurring microorganisms grown on PDA medium (A) after one week of incubation at $25^{\circ} \mathrm{C}$. (A and $C$ ) plating was done with washing water of untreated apples. (B and D) plating was done with a suspension of strain Ach $1-1\left(100 \mu \mathrm{L}\right.$ at $\left.1000 \mathrm{cfu} \mathrm{mL}^{-1}\right)$ and either subjected (B) or not (D) to the laboratory microflora for $3 \mathrm{~h}$.

against the fruit microflora except for some white and yellow yeast colonies morphologically different from A. pullulans strains. In contrast, PDA medium was covered with several types of yeasts, fungi and bacteria (Fig. 5 ).

\section{Discussion}

A. pullulans strains Ach 1-1 and 1113-5 are two new potential biocontrol agents recently isolated from apple fruit surface and selected for their great effectiveness against $P$. expansum and $B$. cinerea (Achbani et al., 2005). The ability of strain Ach1-1 to suppress $P$. expansum development was repeatedly observed both in vitro and in situ (Krimi Bencheqroun et al., 2006). Competition for apple nutrients would be one of the main mechanisms underlying its biocontrol activity on stored apple fruit, amino acids being the most limited nutrients (Krimi Bencheqroun et al., 2007). Among these amino acids, glycine, glutamic acid and especially serine appear to be the most limited nutrients in this mechanism. In a recent study (Mounir et al., 2007), it was found that strain Ach 1-1 was very effective in controlling blue mould on apples at both $5^{\circ} \mathrm{C}$ and $25^{\circ} \mathrm{C}$ and that biomass production in a fermentor (fed-batch) as well as drying (fluidized bed) did not affect its antagonistic activity. As new potential biocontrol agents, the specific identification of strains Ach 1-1 and 1113-5 using monitoring tools is needed for their practical application and for their commercial use.

Methods developed to monitor biocontrol agents can be microbiological (classical or culture-based), direct or molecular methods (for a review, see Pujol, 2006). In all cases, we can differentiate the detection method (unambiguous identification by a specific marker) from the quantification method (assessment of population size). Regarding monitoring biological control agents, combined methods are increasingly used in order to overcome the drawbacks of using a single microbiological, direct or molecular method (e.g. Atkins et al., 2003; Pujol, 2006 and references therein). In the present work, we have developed a mixed monitoring method (SCAR markers and a semi-selective medium) for the specific detection and quantification of A. pullulans strains Ach 1-1 and 1113-5.

Using the RAPD technique, we have identified eight specific RAPD markers (five for Ach 1-1 and three for 1113-5, Table 3). For each strain, one specific marker was chosen for its short sequence size, thus simplifying the later cloning and sequencing steps: a fragment of $528 \mathrm{bp}$ generated with OPR-13 primer for strain Ach 1-1 (Fig. 1) and another one of $431 \mathrm{bp}$ obtained with OPQ-03 primer for strain 1113-5 (Fig. 2). Although these RAPD markers can be used to identify our strains, we chose to convert them into SCAR markers which (i) simplify the detection with a single band instead of a profile, (ii) are more specific as they target a known sequence and (iii) are less sensitive due to stringency of the PCR conditions. To this end, RAPD fragments were cloned and sequenced and a set of SCAR primers was designed (Table 2). In the case of strain Ach 1-1, two SCAR markers were generated: a first one of $189 \mathrm{bp}$ with the primer pair AR13.7/AR13.10 (Fig. 3) and a second one of $387 \mathrm{bp}$ with the primer pair AR13.7/AR13.11 (data not shown). Regarding strain 1113-5, one SCAR marker of $431 \mathrm{bp}$ was amplified with the primer pair AQ3.1/AQ3.2 (Fig. 4). It would be interesting in the future to use these SCAR markers (obtained by conventional PCR) to follow the population dynamics of our strains in different environments by real time PCR. SCAR-based real time PCR has, in fact, been successfully used to monitor several biological control agents such as $A$. pullulans strain L47 (Schena et al., 2002), Plectosphaerella cucumerina (Atkins et al., 2003), Candida oleophila strain O (Massart et al., 2005), Pseudomonas fluorescens strain EPS62e (Pujol et al., 2006), and Trichoderma atroviride strain T1 (Cordier et al., 2007). Although this technique has proven to be more advantageous (speed, accuracy and sensitivity) than the conventional PCR, it is expensive and requires extensive work where a careful examination of (i) the fluorescent signal chemistry, (ii) the design of specific primers and probes and of (iii) the strategy used to establish a standard curve is needed to generate reliable and meaningful results. Our next step will thus be to test whether our SCAR markers could be used in real time PCR experiments. Once implemented, real time PCR, unlike conventional PCR, will not rely on data from counting cfu on semiselective medium to provide an estimation of the population size of the biocontrol agent.

The total number of $A$. pullulans strains used in studies dealing with genetic diversity and/or molecular marker development for monitoring ranged from 10 to 205 strains (Li et al., 1996; Urzi et al., 1999; Schena et al., 1999, 2002; De Curtis et al., 2004; Loncaric et al., 2008). In the present work, SCAR primer pairs were tested on 14 strains of A. pullulans, and on eight strains of other yeast species commonly found on apple fruit, among which four can be used as biocontrol agents (Pichia anomala strains K and J121, C. oleophila strains O and I-128) (Table 1). The specificity of our SCAR primer pairs was also checked using DNA template extracted from the epiphytic microflora of apple surface (detailed data not shown). Because of the high diversity/wide distribution of A. pullulans (Yurlova et al., 1995; Schena et al., 1999; Urzi et al., 1999; this work, Fig. 2) and the small number of strains tested in the present work, it would be useful to validate the specificity of our SCAR markers by testing in the future these primers on a large number of strains issued from different substrates and sites, including those used by other biological control research groups (e.g. LS30, L47, CF10, CF40, etc.). Interestingly, we have in the present work other RAPD markers (four for Ach 1-1 and two for 1113-5), which constitute new potential SCAR markers if those generated here become nonspecific to our strains.

Although SCAR marker development requires long efforts and high cost equipment, they are less time consuming, more sensitive and culture independent once developed. SCAR markers have thus 
been successfully developed for several biological agents, including those belonging to A. pullulans species (Schena et al., 2002; De Clercq et al., 2003; Pujol et al., 2005; Nunes et al., 2008; Loncaric et al., 2008). However, the fact that such kinds of markers may not differentiate dead cells from living cells, and therefore might overestimate the viable cells, constitutes their most important drawback. This would be overcome in the present work since our monitoring system also relies on counting cfu on a semi-selective medium allowing simple identification and quantification of our strains by the classical dilution plating method. To our knowledge, the $S_{32}$ medium $\left(0.5 \mathrm{mg} \mathrm{L}^{-1}\right.$ euparen $+1 \mathrm{mg} \mathrm{L}^{-1}$ sumico $+2.5 \mathrm{mg} \mathrm{L}^{-1}$ hygromycin $\mathrm{B}+30 \mathrm{mg} \mathrm{L}^{-1}$ streptomycin sulphate $+1 \mathrm{mg} \mathrm{L}^{-1}$ cycloheximide, Table 5) using PDA as the basal medium is the first semi-selective medium developed for the isolation and quantification of biocontrol agents belonging to the A. pullulans species. It is composed of two fungicides [euparen (Tolylfluanide), sumico (carbendazim and diethofencarb)] and three antibiotics (hygromycin B, streptomycin sulphate, cycloheximide). It prevented the growth of laboratory air microflora (Fig. 5) and was not toxic for strains Ach 11 and $1113-5$ (plating efficiency more than $90 \%$, Table 5). The ability of the $S_{32}$ medium to inhibit the natural microorganisms present on apple surface was checked (Fig. 5). This point is of major importance since the semi-selective medium will be used to quantify the antagonist population on apple surface. Although this medium does not distinguish between our strains and other closely related ones, the application of a simple PCR on the plated colonies using the specific SCAR primers will specifically identify strains Ach $1-1$ and 1113-5. Other studies have also exploited the benefits of the dilution plating method on a semi-selective medium with strain-specific identification by SCAR markers (Abbasi et al., 1999; De Clercq et al., 2003; Pujol et al., 2005; Nunes et al., 2008). The combined use of at least two different methods has been considered as a necessary and powerful tool for the monitoring, detection and quantification of biocontrol agents (Atkins et al., 2003; Pujol et al., 2006).

The use of the semi-selective medium and SCAR markers we have developed in the present work as a mixed system to monitor and quantify $A$. pullulans strains Ach 1-1 and 1113-5 may be of some importance. The practical application of these strains requires a valid monitoring system to specifically detect them within complex populations, follow their population dynamics in relation to modality of application, formulation and environmental conditions, and to assess their dispersion and persistence once released in the environment. However, more research is still needed mainly to test our SCAR markers on a large set of A. pullulans from different hosts and geographical origins, with emphasis on apple surface epiphytes for a specific detection and quantification of our strain populations.

\section{Acknowledgements}

This work was financially supported by DGCD-CUD (Direction Général de la coopération au Développement - Commission Universitaire pour le Développement) as PIC (Projet Interuniversitaire Ciblé) - Morocco project. We thank L. Masquelier and A. Benbouazza for their technical assistance.

\section{References}

Abbasi, P.A., Miller, S.A., Meulia, T., Hoitink, H.A.J., Kim, J.-M., 1999. Precise detection and tracing of Trichoderma hamatum 382 in compost-amended potting mixes by using molecular markers. Appl. Environ. Microbiol. 65, 5421-5426.

Achbani, E.H., Mounir, R., El Jaafari, S., Douira, A, Benbouazza, A. Jijakli, M.H., 2005. Selection of antagonists of postharvest apple parasites: Penicillium expansum and Botrytis cinerea. Commun. Appl. Biol. Sci., Ghent University 70, 143-149.

Ajello, L., 1977. The black yeasts as disease agents: historical perspective. PAHO 324 9-16.
Atkins, S.D., Clark, I.M., Sosnowska, D., Hirsch, P.R., Kerry, B.R., 2003. Detection and quantification of Plectosphaerella cucumerina, a potential biological control agent of potato cyst nematodes, by using conventional PCR, real-time PCR, selective media, and baiting. Appl. Environ. Microbiol. 69, 4788-4793.

Ausubel, F.M., Brent, R., Kingston, R.E., Moore, D.E., Seidman, J.G., Smith, J.A., Struhl, K., 1987. Preparation of yeast DNA. In: Ausubel, F.M., Brent, R., Kingston, R.E. Moore, D.E., Seidman, J.G., Smith, J.A., Struhl, K. (Eds.), Current Protocols in Molecular Biology, vol. 2. John Wiley, New York, pp. 13.11.2.

Castoria, R., De Curtis, F., Lima, G., Caputo, L., Pacifio, S., De Cicco, V., 2001. Aureobasidium pullulans (LS-30) an antagonist of postharvest pathogens of fruits: study on its mode of action. Postharvest Biol. Technol. 22, 7-17.

Cordier, C., Edel-Hermann, V., Martin, L., Blal, B., Steiberg, C., Alabouvette, C., 2007. SCAR-based real time PCR to identify a biocontrol strain (T1) of Trichoderma atroviride and study its population dynamics in soils. J. Microbiol. Methods 68, $60-68$.

De Clercq, D., Cognet, S., Pujol, M., Lepoivre, P., Jijakli, M.H., 2003. Developement of a SCAR marker and a semi-selective medium for specific quantification of Pichia anomala strain K on apple fruit surfaces. Postharvest Biol. Technol. 29, 237-247.

De Curtis, F., Caputo, L., Castoria, R., Lima, G., Stea, G., De Cicco, V., 2004. Use of fluorescent amplified fragment length polymorphism (fAFLP) to identify specific molecular markers for the biocontrol agent Aureobasidium pullulans strain LS30. Postharvest Biol. Technol. 34, 179-186.

Domsch, K.H., Gams, W., Anderson, T.H., 1980. Compendium of soil fungi, vol. 1. Academic Press, London.

Donegan, K., Matyac, C., Seidler, R., Porteous, A., 1991. Evaluation of methods for sampling, recovery, and enumeration of bacteria applied to the phylloplane. Appl. Environ. Microbiol. 57, 51-56.

Hermanides-Nijhof, E.J., 1977. Aureobasidium and allied genera. Stud. Mycol. 15 141-177.

Ippolito, A., El Ghaouth, A., Wilson, C.L., Wisniewski, M., 2000. Control of postharvest decay of apple fruit by Aureobasidium pullulans and induction of defense responses. Postharvest Biol. Technol. 19, 265-272.

Krimi Bencheqroun, S., Bajji, M., Massart, S., Bentata, F., Labhilili, M., Achbani, E.H. El Jaafari, S., Jijakli, M.H., 2006. Biocontrol of blue mold on apple fruits by Aureobasidium pullulans (strain Ach 1-1): In vitro and in situ evidence for the possible involvement of competition for nutrients. Commun. Appl. Biol. Sci., Ghent University 71, 1151-1157.

Krimi Bencheqroun, S., Bajji, M., Massart, S., Labhilili, M., El Jaafari, S., Jijakli, M.H., 2007. In vitro and in situ study of postharvest apple blue mold biocontrol by Aureobasidium pullulans: evidence for the involvement of competition for nutrients. Postharvest Biol. Technol. 46, 128-135.

Lee, J.W., Yeomans, W.G., Allen, A.L., Deng, F., Gross, R.A., Kaplan, D.L., 1999 Biosynthesis of novel exopolymers by Aureobasidium pullulans. Appl. Environ. Microbiol. 65, 5265-5271.

Leibinger, W., Breuker, B., Hahn, M., Mendgen, K., 1997. Control of postharvest pathogens and colonization of the apple surface by antagonistic microorganisms in the field. Phytopathology 87, 1103-1110.

Li, S., Cullen, D., Hjort, M., Spear, R., Andrews, J.H., 1996. Development of an oligonucleotide probe for Aureobasidium pullulans Based on the small-subunit rRNA gene. Appl. Environ. Microbiol. 62, 1514-1518.

Loncaric, I., Donat, C., Antlinger, B., Oberlerchner, J.T., Heissenberger, B., Moosbeckhofer, R., 2008. Strain-specific detection of two Aureobasidium pullulans strains, fungal biocontrol agents of fire blight by new, developed multiplex-PCR. J. Appl. Microbiol. 104, 1433-1441.

Massart, S., De Clercq, D., Salmon, M., Dickburt, C., Jijakli, M.H., 2005. Development of real-time PCR using minor groove binding probe to monitor the biologica control agent Candida oleophila (strain O). J. Microbiol. Methods 60, 73-82.

Mounir, R., Durieux, A., Bodo, E., Allard, C., Simon, J.-P., Achbani, E.H., El Jaafari, S. Douira, A., Jijakli, M.H., 2007. Production, formulation and antagonistic activity of the biocontrol like-yeast Aureobasidium pullulans against Penicillium expansum. Biotechnol. Lett. 29, 553-559.

Nunes, C., Bajji, M., Stepien, V., Manso, T., Torres, R., Usall, J., Jijakli, M.H., 2008. Development and application of a SCAR marker to monitor and quantify populations of the postharvest biocontrol agent Pantoea agglomerans CPA-2. Postharvest Biol. Technol. 47, 422-428.

Olive, D.M., Bean, P., 1999. Principles and applications of methods for DNA-based typing of microbial organisms. J. Clin. Microbiol. 37, 1661-1669.

Paran, I., Michelmore, R.W., 1993. Development of reliable PCR-based markers linked to downy mildew resistance genes in lettuce. Theor. Appl. Genet. 85, 985-993.

Pujol, M., 2006. Development of molecular monitoring methods and assessment of the environmental fate of the biological control agent of fire blight Pseudomonas fluorescens EPS62e. Doctoral thesis, Universitat de Girona.

Pujol, M., Badosa, E., Manceau, C., Montesinos, E., 2006. Assessment of the environmental fate of the biological control agent of fire blight, Pseudomonas fluorescens EPS62e, on apple by culture and real-time PCR methods. Appl. Environ. Microbiol. 72, 2421-2427.

Pujol, M., Badosa, E., Cabrefiga, J., Montesinos, E., 2005. Development of a strainspecific quantitative method for monitoring Pseudomonas fluorescens EPS62e, a novel biocontrol agent of fire blight. Microbiol. Lett. 249, 343-352.

Schena, L., Ippolito, A., Zahavi, T., Cohen, L., Nigro, F., Droby, S., 1999. Genetic diversity and biocontrol activity of Aureobasidium pullulans isolates against postharvest rots. Postharvest Biol. Technol. 17, 189-199.

Schena, L., Sialer, M.F., Gallitelli, D., 2002. Molecular detection of strain L47 of Aureobasidium pullulans, a biocontrol agent of postharvest diseases. Plant Dis. 86 $54-60$. 
Sterflinger, K., 2005. Black yeasts and meristematic fungi: ecology, diversity and identification. In: Rosa, C., Gabor, P. (Eds.), The Yeast Handbook vol. 1: Biodiversity and Identification of Yeasts. Springer, New York, pp. 505-518.

Teixido, N., Usall, J., Vinas, I., 1999. Efficacy of preharvest and postharvest Candida sake biocontrol treatments to prevent blue mold on apples during cold storage. Int. J. Food Microbiol. 50, 203-210.

Urzi, C., De Leo, F., Lo Passo, C., Criseo, G., 1999. Intraspecific diversity of Aureobasidium pullulans strains isolated from rocks and other habitats assessed by physiological methods and by random amplified polymorphic DNA (RAPD). J. Microbiol. Methods 36, 95-105.
Williams, J.K.G., Kubelik, A.R., Livak, K.J., Rafalski, J.A., Tingey, S.V., 1990. DNA polymorphisms amplified by arbitrary primers are useful as genetic markers. Nucleic Acids Res. 18, 6531-6535.

Yurlova, N.A., Mokrousov, I.V., de Hoog, G.S., 1995. Intraspecific variability and exopolysaccharide production in Aureobasidium pullulans. Ant. Leeuwenhoek 68, 57-63.

Yurlova, N.A., de Hoog, G.S., 1997. A new variety of Aureobasidium pullulans characterized by exopolysaccharide structure, nutritional physiology and molecular features. Ant. Leeuwenhoek 72, 141-147. 